\title{
A multiple sclerosis-associated virus: past, present and future ${ }^{\star}$
}

\author{
R. I. Carp, G. S. Merz, P. A. Merz and P. C. Licursi
}

\section{Introduction}

The search for the cause of multiple sclerosis (MS) was initially wide in scope and has only recently begun to centre upon virus. Over the past few years our laboratory has accumulated convincing evidence of a high degree of association of a small virus-like agent with MS. In this report, we will give the rationale of our approaches, summarize our results and provide a brief discussion of the salient points raised by the data.

Our studies on MS began in I97I when we attempted to settle the question raised by reports in the early I960s from the laboratories of Palsson ${ }^{\mathrm{I}}$ and Field $^{2}$. In these early studies CNS disease occurred in sheep and mice following inoculation with MS autopsy material. The disease had neither the clinical nor the histopathological features of MS. Instead it was indistinguishable from scrapie, a slow, degenerative encephalopathy that occurs naturally in sheep and experimentally in mice ${ }^{3}$. According to the first report, sheep inoculated with the MS material developed scrapie-like disease several years later. The disease was successfully transmitted from sheep to sheep with a shorter incubation period than in the human-to-sheep inoculation. In the second report ${ }^{2}$, mice inoculated with MS material were clinically normal when sacrificed 8 months later. Their brains were then placed in formalin for pathology studies. Later, acting on a report that scrapie agent is extremely

* This work was supported in part by Grants 723 B-2 and RG 979 A-5 from the National Multiple Sclerosis Society. 
resistant to inactivation by formalin, the formalinized brains were homogenized and the homogenates were inoculated into mice. Between $\mathrm{I} 3$ and I7 months later the inoculated mice were sacrificed and some showed pathology typical of scrapie. After the third serial passage in mice, clinical scrapie developed in 5 to 6 months. Although the possibility of contamination of the sheep and/or mice with scrapie seems unlikely since test animals were maintained in areas free of scrapie, the question of contamination of the inoculum at some point has never been resolved. Furthermore, the significance of these results is clouded by the fact that despite numerous attempts these findings have not been duplicated. ${ }^{\star}$

Based on work we have reported elsewhere ${ }^{4,5}$, we can suggest an explanation of these anomalous results which can be generalized into a novel but potentially important concept. One can view pathogenesis as a sequence of discrete events that begins at the subcellular or cellular level, and culminates in functional disintegration at the level of organs or organ systems. It is the last stage that generates the clinical disease state. It is self-evident that the failure to complete any of the preceding events could block the overall process and prevent the development of clinical disease. It is possible, however, that events occurring before the block might lead to alterations in the host that: (I) would not be debilitating, (2) would persist indefinitely, perhaps for the life of the host, and (3) would leave the animal in a 'primed' state for the resumption of the process if ever the block were somehow removed or bypassed.

The above assumptions could explain what might be a real but sporadic transmission of a disease from MS to healthy sheep and/or mice. One need only assume that all transmission attempts were successful in that something (a virus?) was transmitted to the test host but that the culmination of the pathological processes was somehow prevented or aborted. Those few cases in which disease was observed would then represent rare instances in which the block had been bypassed.

It was with this concept in mind that we began a search for 'preblock' alterations in mice inoculated with MS autopsy material. We were looking specifically for alterations similar to those known to occur in the early, preclinical period of scrapie disease. These changes included alterations in brain enzyme activities 6 , differences in water and food consumption ${ }^{7}$ and alterations in the protein patterns seen in the electropherograms of mouse

* Editor's note: Unknown to Palsson, Pattison and Field (I965), transfer of the Newcastle material into new containers for transport purposes took place in a laboratory intermediate between Newcastle and Reykjavik, in which scrapie work was active. The association of scrapie with MS has been withdrawn (see Chapter 9), on the basis that scrapie sheep do not give MS results with the laboratory tests developed. 
cerebrospinal fluid $(\mathrm{CSF})^{8}$. In addition to the above, we tested several routine parameters including leukocyte differentials in the peripheral blood. The most striking finding was a 2-to-3-fold decrease in the percentages of circulating polymorphonuclear neutrophils $(\mathrm{PMN})^{4,5}$. This was found in mice inoculated with either scrapie or MS brain homogenates, whereas mice inoculated with normal mouse or human brain homogenates had PMN percentages similar to those found for uninoculated mice4.5. These results will be discussed in detail in a subsequent section, but as an introductory point it should be mentioned that the agent causing the decrease in PMN could be passed from mouse to mouse and replicated in mice. For this reason, we were interested in determining if this agent would replicate in a spontaneously transformed mouse tissue culture cell-line termed PAM. During the course of this work we observed that MS material caused a reduction in cell yield as compared to the yield obtained for non-MS treated or control PAM cell cultures ${ }^{9-12}$. These data will also be discussed in detail in the Results section. Also, in keeping with the original objective of our work, the effects of scrapie material on both the PMN percentage in mice ${ }^{5}$ and the yield of PAM cells ${ }^{13}$ were analysed and these results are outlined.

\section{Results}

\section{THE PMN DECREASE}

In our initial work, mice injected either intracerebrally (IC) or intraperitoneally (IP) with a pool of three brain homogenates, developed a decrease in the per cent of circulating PMN that was detected as early as two weeks, and persisted for at least I6 months. During this period no other histopathological or clinical change was observed. Counts of the total number of PMN and lymphocytes established that the reduction was due to a real decrease in the number of PMN, as opposed to an apparent decrease engendered by an increase in the number of lymphocytes or other white cell types. The agent causing the decrease replicated in mice and was readily passed from mouse to mouse. The agent was present at titres of $\mathrm{IO}^{\mathrm{II}} / \mathrm{g}$ to ${ }^{10} \mathrm{I}^{12} / \mathrm{g}$ in the human MS brain pool and at similar titres in the brains of inoculated mice. Based on millipore filtration, the diameter of the agent was between 25 and $50 \mathrm{~nm}$.

These results constitute the first evidence to indicate clearly the existence of an MS-associated virus. Figure 5.I gives a picture of the distribution of the PMN percentage among MS and control-inoculated mice. Although there is some overlap of the control distributions with the MS, the difference is clear. Based on these data, we established a PMN percentage of to as the 


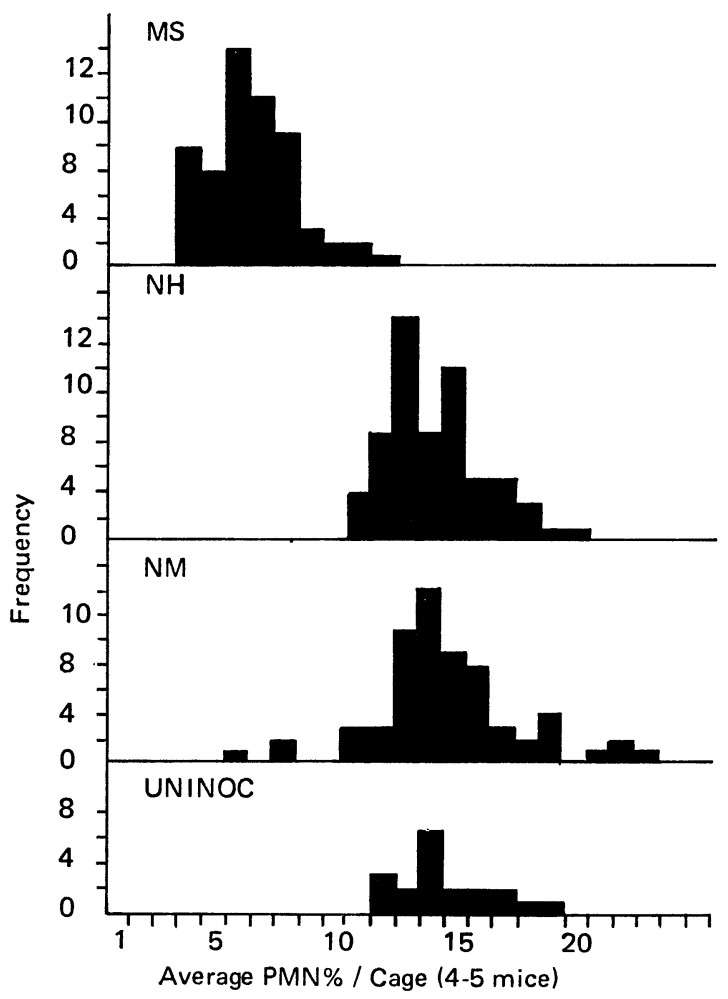

Figure 5.I Frequency distribution of average PMN percentage of four or five mice. MS $=$ multiple sclerosis $; \mathrm{NH}=$ normal human $; \mathrm{NM}=$ normal mouse $;$ Uninoc = uninoculated

basis for deciding whether a sample is positive (PMN \% $\leqslant$ Io) or negative (PMN \% > Io).

\section{ASSOCIATION OF THE PMN AgENT WITH MS TISSUES}

Our next step was to determine the extent to which the agent/virus was (I) present in MS tissue samples, and (2) specific for MS disease. Table 5.I shows the distribution and description of the diseases that were tested in this phase of the work, Table 5.2 shows the distribution of tissues among the sample collection.

After testing samples both directly by inoculation into mice and indirectly by blind passage from mouse to mouse, we arrived at the following conclusions:

(I) The average PMN percentage of mice inoculated with MS material 
Table 5.I Diseases represented in sample collection

\begin{tabular}{lccc}
\hline Disease class & Disease or MS status & Number of cases & Number of samples \\
\hline Healthy & 24 & 28 \\
Total & 24 & 28
\end{tabular}

Non-CNS

Vaginal herpes

Cirrhosis

Pneumonia

Arteriosclerosis

Pancreatitis

Melanoma

Liver necrosis

Lumbosacral strain

Lumbar radiculitis

CVA

No diagnosis

$\begin{array}{rr}\text { I } & \text { I } \\ \text { I } & \text { 2 } \\ \text { I } & \text { I } \\ \text { I } & \text { I } \\ \text { I } & \text { I } \\ \text { I } & \text { I } \\ \text { I } & \text { I } \\ \text { I } & \text { I } \\ \text { I } & \text { I } \\ 3 & 3 \\ \text { I } & \text { I } \\ \text { I3 } & \text { I4 }\end{array}$

Total

CNS

Total

$\begin{array}{lcr}\text { Encephalopathy } & \text { I } & \text { I } \\ \text { Bechat's syndrome } & \text { I } & \text { I } \\ \text { SSPE } & 8 & 9 \\ \text { Epilepsy } & \text { I } & \text { I } \\ \text { Demyelination } & \text { I } & 2 \\ \text { Spongy degeneration } & \text { I } & 2 \\ \text { Myoclonic lipidosis } & \text { I } & \text { I } \\ \text { Huntington's chorea } & 3 & 5 \\ \text { Parkinson's disease } & 5 & 6 \\ \text { Cerebral palsy } & \text { I } & \text { I } \\ \text { Spinal cerebral degeneration } & 2 & 2 \\ \text { Alcoholic cerebral degeneration } & \text { I } & \text { I } \\ \text { EAE (rat) } & 9 & 9 \\ \text { Presenile dementia } & \text { I } & \text { I } \\ & 36 & \mathbf{4 2}\end{array}$

MS

Autopsy
No information
Retrobulbar neuritis (RBN)
Stage I-III
Stage IV-VI
Serial bleeds

Total

$\begin{array}{rr}\text { IO } & \text { I4 } \\ 2 \mathrm{I} & 2 \mathrm{I} \\ 4 & 8 \\ 5 & 7 \\ 5 & \text { IO } \\ 2 & 8 \\ 47 & 68\end{array}$


Table 5.2 Distribution of tissues among the disease classes

\begin{tabular}{lcccc}
\hline & \multicolumn{5}{c}{ Class of disease } \\
\cline { 2 - 5 } Tissue (152) & $M S(68)$ & CNS (42) & Non-CNS (14) & Healthy (28) \\
\hline Brain (17) & 8 & 3 & 6 & 0 \\
CSF (39) & 26 & 4 & 2 & 7 \\
Serum (86) & 28 & 33 & 4 & $2 \mathrm{I}$ \\
Spleen (6) & 3 & $\mathrm{I}$ & 2 & 0 \\
Lymph gland (I) & $\mathrm{I}$ & 0 & 0 & 0 \\
Kidney (3) & 2 & $\mathrm{I}$ & 0 & 0 \\
\hline
\end{tabular}

* Number in parentheses is the total number in each tissue of class or disease.

was lower than that for mice inoculated with healthy, CNS or non-CNS material.

(2) If the criteria for detecting the presence of the PMN factor includes the capacity to cause the PMN drop on mouse passage, as it should with an infectious agent, then $73 \%$ of MS samples were positive and only $20 \%$ of CNS and other non-MS samples were positive.

(3) A significant number of MS samples that were negative on primary inoculation were positive on mouse-to-mouse passage, while the reverse trend was observed with the CNS samples.

(4) Multiple samples from one individual were usually all positive or all negative.

(5) In human material, the agent has been found in every type of tissue examined. These include brain, spleen, kidney, lymph gland, serum and CSF.

Our results with the PMN factor have recently been confirmedi4.15 in virtually every detail. In addition, these workers made a number of additional findings: (I) the PMN decrease was induced in a number of other mouse strains, and in several different species, including guinea-pig, rat and hamster, (2) a neutralizing antibody to the PMN factor was found in a number of MS patients and in close contacts of patients, such as relatives, nurses and doctors, and in blood samples from East Africans. In contrast, sera from a sampling of the normal population in the United States showed that virtually none contained neutralizing antibody.

Two other studies, each encompassing a small series of experiments employing comparatively few mice, failed to confirm our basic findings ${ }^{16,17}$. One group, however, did find a statistically significant change in the leukocyte distribution in mouse bone marrow induced by MS inoculation ${ }^{17}$. Failure with this test can often be related to problems with the physiological 
and/or medical status of the mice, and careful control of these parameters is critical. This will be discussed in detail in a subsequent section.

\section{Reduction in PMN percentages in scrapie-inoculated mice}

The experiments with scrapie in mice were initiated at the same time as the MS studies. A decrease in the percentage of PMN in the peripheral blood of mice appeared three days after IC inoculation with scrapie mouse brain homogenate ${ }^{5}$; IP inoculation was also effective in causing a decrease in PMN percentage. Mice inoculated IC or IP with normal mouse brain had PMN percentages similar to those found for uninoculated mice. This difference between normal and scrapie-inoculated mice continued throughout the preclinical phase of the disease. In the clinical phase of the disease, the percentage of PMN was either higher or lower than that found in normals. The factor causing the decrease in PMN percentages was found in the filtrates from 220, 100 and $50 \mathrm{~nm}$ filters, but not in the filtrates from a $25 \mathrm{~nm}$ filter. In addition to two genetically different scrapie mouse brain isolates, homogenates of mouse spleen, sheep brain and sheep spleen from scrapie-affected animals caused a decrease in per cent PMN, whereas the corresponding normal tissue homogenates did not. We have also shown that the titre of the agent causing the reduction in PMN is approximately $10^{6}$ times greater than the infectivity titre of scrapie ${ }^{18}$. The PMN agent replicated in mice that never showed signs of scrapie, i.e. mice inoculated with approximately $6 \times 10^{-4} \mathrm{LD}_{50}$ units of scrapie. Nine weeks after inoculation with 100 units of PMN agent (but no scrapie) mouse brain contained ${ }^{1} \mathrm{II}^{\mathrm{II}}$ units of PMN agent. Inoculation of mice with $\mathrm{IO}^{\mathrm{II}}$ units of PMN agent, which had been produced in the absence of scrapie infectious units, failed to cause scrapie disease ${ }^{18}$. Thus, the scrapie infectious unit and the PMN agent are separable, although the PMN agent is always found in conjunction with scrapie disease.

Dickinson et al. ${ }^{19}$ have shown a reduction in $\mathrm{PMN}$ percentages in $\mathrm{C}_{57} \mathrm{BL}$ mice following inoculation with six different scrapie agents that had been passaged and characterized in mice. Furthermore, these authors reported that six sources of scrapie from sheep and two from goats ('scratching' and 'drowsy' types) caused a significant reduction in PMN percentages.

\section{ASSESSMENT OF THE PMN TEST FOR MS-ASSOCIATED VIRUS}

In spite of the success in establishing that there is undoubtedly a virus-like agent associated with MS tissues, the PMN test has some severe limitations and shortcomings ${ }^{14-16,19}$. First, the health of the mice is critical. We have had numerous recent mouse shipments from many various suppliers which, on the day of arrival, had severe chronic interstitial pneumonitis or chronic 
bronchitis. These mice were completely asymptomatic, with no increase in mortality. The only overt manifestations of the disease were a reduced level of circulating PMN, increased variability in lymphocyte and the PMN counts, and on occasion, a slight increase in the number of immature lymphocytes. Inoculation of these mice with MS material failed to produce any noticeable effect, since the PMN counts were so low and variable prior to inoculation. The results obtained when we tested these mice were similar to those reported by Brown and Gajdusek ${ }^{16}$ in several of their experiments.

On other occasions we had rounds of a disease of unknown origin and aetiology. This 'plague' was characterized by (I) an increased number of immature lymphocytes, and (2) abnormally high variation in PMN percentages among the mice. Compared to healthy mice the mean PMN percentage among mice inoculated with MS brain pool was elevated slightly and was indistinguishable from those inoculated with normal brain pool. More telling, however, was the increase of 2 - to $2 \cdot 5$-fold in the standard deviations of the PMN values for mice inoculated with both MS and normal brain pools over that obtained using healthy mice.

Third, because of the normal responses to trauma (increased circulating PMN) and various husbandry factors, a number of other parameters should be carefully controlled. These include the following:

(I) Repeated bleeding of the same mouse at intervals of less than two weeks should be avoided.

(2) Ear snipping and all other procedures that result in tissue damage should be avoided.

(3) Always bleed mice at the same time of day and ensure that noise and disturbance are kept to a minimum.

(4) If fighting occurs in a cage, the attendant wounds and infections will obviously render the PMN values of mice in that cage worthless. For this reason, we routinely use female mice, which are considerably less aggressive than males.

Quite aside from these considerations, there is also the problem of the distributions of the MS and control PMN percentages overlapping, and our criteria for whether a sample is positive or negative is therefore somewhat arbitrary. This is particularly vexing when it comes to interpreting the significance of negative MS samples and, more importantly, positive non-MS samples. When all the above are considered, the PMN test becomes unwieldy and unworkable for further work, such as characterization of the agent, etc. It was with these considerations in mind that we began searching for a more facile test for the MS-associated virus. 
MS-INDUCED DECREASE IN TOTAL CELL YIELD OF PAM CELL CULTURES

Our search began with an attempt to determine whether the MS-associated virus could replicate in cells in vitro. MS tissue was applied to PAM cells, a spontaneously transformed mouse cell-line derived from mouse embryo fibroblasts of CFW random-bred mice. Our original intent was simply to inoculate mice with PAM cell culture samples I6-I 8 passages after treatment with MS material and look for a PMN reduction. To our surpirse, there was a direct response to MS tissues; a decrease in the total cell yield. Reductions in cell yield were noted as early as the second passage after treatment. The effect was produced by eight of eight MS brain homogenates and three of three MS spleen homogenates; the samples were from ten different cases9. The reduction in total cell yields was not observed among PAM cultures treated with non-MS homogenates (six brain and two spleen) from eight control individuals. Five of the MS-inoculated cultures were maintained for I8 subcultivations, and the reduced cell yields persisted throughout (Figure 5.2). The agent responsible for the reduction was present in the cell-free

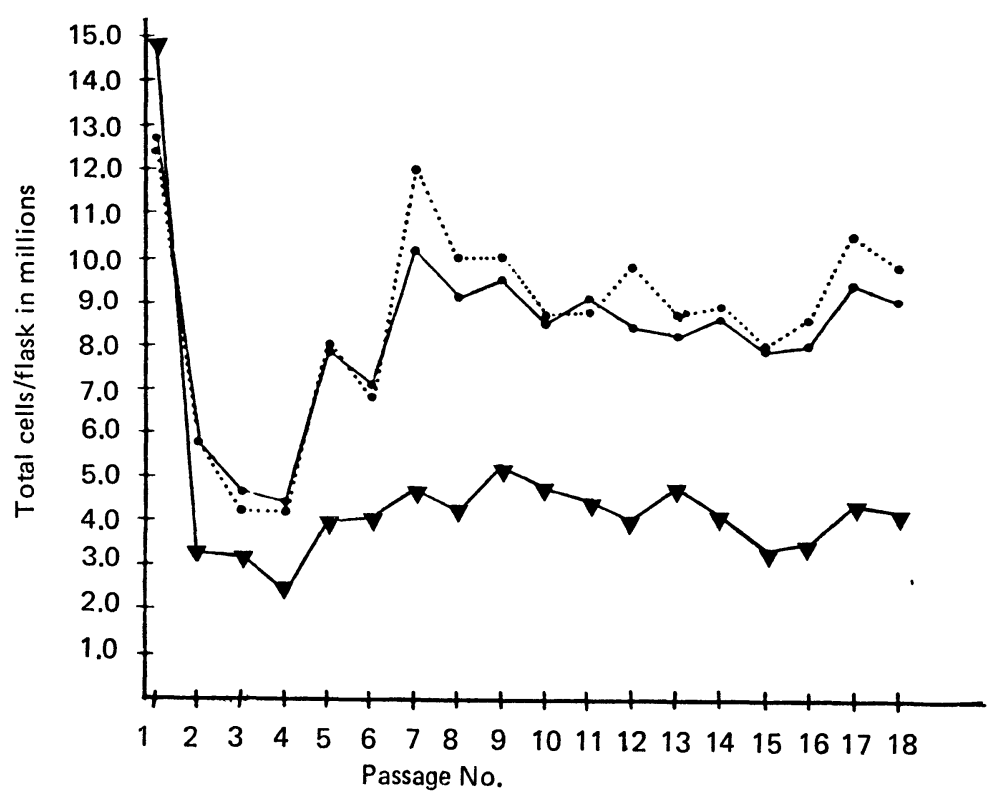

Figure 5.2 Total cell yield per flask as a function of culture passage number averaged cell yield of four non-MS treated cultures; $\boldsymbol{\nabla}$ - average cell yield of five MS-treated cultures; - - - - cell yield of medium-treated culture 
lysates (prepared by repeated freezing and thawing) from all of the five MS cultures at passage 18 , in that treatment of fresh PAM cells with these lysates led to a reduction in PAM cell yields. Inoculation of the lysates into mice caused a reduction in PMN implying the presence of the PMN agent (Table 5.3). Calculation of the dilution effect (at least ${ }_{10}{ }^{18}$-fold) that had occurred by the end of the passage series implies that the agent(s) causing the decreased

Table 5.3 Effect of MS-treated PAM cell lysates on PAM cell cultures and polymorphonuclear neutrophil percentages in mice

\begin{tabular}{|c|c|c|c|}
\hline \multirow[b]{2}{*}{$\begin{array}{c}\text { Treatment } \\
\text { at passage o }\end{array}$} & \multicolumn{2}{|c|}{ Cell yield/flask $\times \mathrm{Io}^{-6}$} & \multirow[b]{2}{*}{$\begin{array}{c}\text { PMN percentage } \\
\text { in mice inoculated } \\
\text { with passage } 18 \text { lysates }\end{array}$} \\
\hline & $\begin{array}{c}\text { At passage } 18 \text { after } \\
\text { exposure }\end{array}$ & $\begin{array}{c}\text { Among PAM cultures } \\
\text { exposed to lysates } \\
\text { prepared from passage } 18 \text { cells }\end{array}$ & \\
\hline N-I & $8 \cdot 5$ & $10 \cdot 6$ & $\mathrm{I} 6 \cdot 0^{\mathrm{a}}(\mathrm{I} \cdot 34)$ \\
\hline $\mathrm{N}-2$ & $8 \cdot 7$ & II 4 & $15 \cdot 6(\mathrm{I} \cdot 2 \mathrm{I})$ \\
\hline $\mathrm{N}-3$ & $9 \cdot 7$ & $10 \cdot 0$ & $15.6(0.51)$ \\
\hline $\mathrm{N}-4$ & $9 \cdot 2$ & II $\cdot 6$ & $17 \cdot 0(1 \cdot 30)$ \\
\hline Average $(\mathrm{SE})^{\mathbf{b}}$ & b $9 \cdot 0^{c}(0 \cdot 3)$ & $10 \cdot 9^{d}(0 \cdot 4)$ & $15^{\circ} 8^{\mathrm{e}}\left(0 \cdot 3^{8}\right)$ \\
\hline MS-I & $4 \cdot I$ & $5 \cdot 3$ & $6.0(0.43)$ \\
\hline MS-2 & $4 \cdot 5$ & $5 \cdot 6$ & $4.2(0.58)$ \\
\hline $\mathrm{MS}-3$ & $3 \cdot 8$ & $4 \cdot 8$ & $2.4(0.5 \mathrm{I})$ \\
\hline $\mathrm{MS}-4$ & $4 \cdot 5$ & $6 \cdot 0$ & $5 \cdot 2(I \cdot 44)$ \\
\hline MS-5 & $4 \cdot 0$ & $5 \cdot 8$ & $5.2(0.97)$ \\
\hline Average (SE) & $4^{\cdot 2^{c}}(0 \cdot 15)$ & $5 \cdot 5^{d}(0 \cdot 2 I)$ & $4 \cdot 6^{e}(0.62)$ \\
\hline
\end{tabular}

a Average (SE) for groups of five mice

b SE standard error

c $P$ of no difference $(t$ test $) \ll 0.001$

d $P$ of no difference $(t$ test $) \ll 0 \cdot 001$

e $P$ of no difference $(t$ test $) \ll 0.001$

PAM cell yield and the PMN decrease in mice had replicated in vitro. Filtration of a pool of five MS brain homogenates through graded pore size millipore filters revealed that the PAM agent is between 25 and $50 \mathrm{~nm}$ in diameter.

\section{ASSOCIATION OF THE PAM AGENT WITH MS TISSUES}

Once again, the question of association with and specificity for MS became crucial. A collection of 7I MS and 45 non-MS samples, composed of unpassed and mouse-passed material was applied to PAM cultures in eight 
separate experiments. Because the yields of PAM cell cultures vary somewhat in a concordant fashion with time and subcultivation, each experiment contained an untreated PAM culture as a control, in addition to MS and non-MS treated cultures. All yields were expressed as the percentage of this untreated control. Whereas the non-MS distribution is unimodal, it appears that the distribution of MS yields is bimodal, with one group distributed similarly to the non-MS and one that is distributed on a much lower range (Figure 5.3). Based on these observations, we have adopted the following convention: all yields (calculated as a percentage of control) less than $80 \%$ are considered as a positive response, whereas all yields equal to or greater than $80 \%$ are considered as no response.

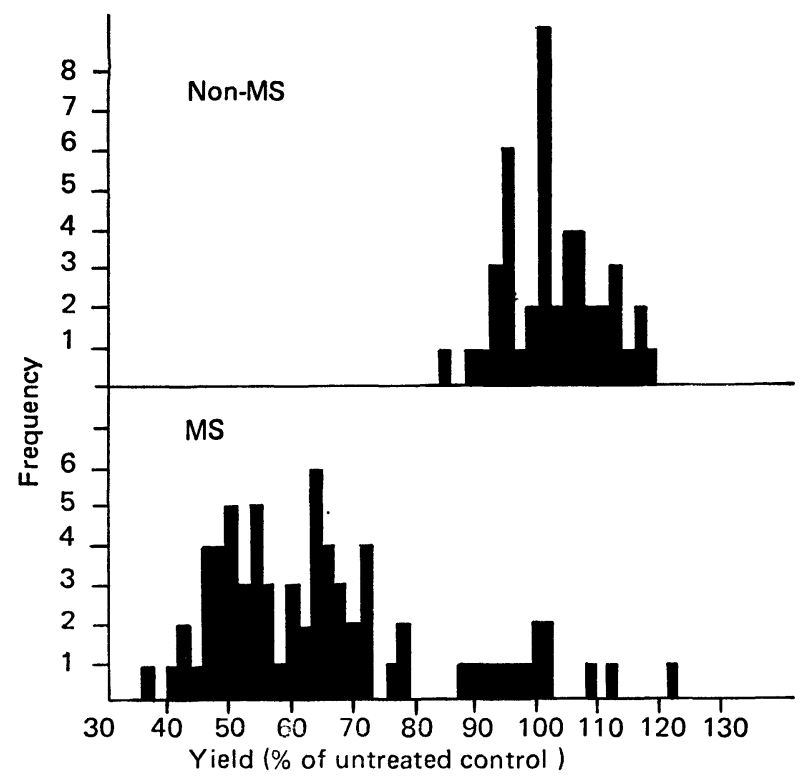

Figure 5.3 Frequency distribution of PAM cell yields as a percentage of yields for untreated controls

Of the PAM cultures treated with MS material, $80 \%$ (58) showed a reduction in cell yield (compared with untreated controls) of at least $20 \%$ by the third passage after inoculation. The MS samples were from 40 different MS cases, and a total of 36 cases yielded at least one positive sample. The agent responsible for the decrase was not limited to brain and spleen tissue, but also was found in serum, plasma, CSF, kidney and lymph 
node of MS patients. Positive samples were present at every stage of the disease.

The non-MS category included I2 samples from healthy individuals, I3 assorted non-CNS disease samples, and the following CNS disease samples: five subacute sclerosing panencephalitis, three Huntington's chorea, two Parkinson's disease, six amytrophic lateral sclerosis, one stroke, one encephalopathy and one epilepsy.

At this point, 48 of the MS and 32 of the non-MS treated PAM cultures were serially passaged through a total of 16 or 17 passages. Yields were determined at passages $3,4,5$ and Io through 16 or I7, expressed as a percentage of the untreated control culture and averaged. All of the averaged cell yields for MS cultures except one were less than $80 \%$ of the untreated control, while the averaged cell yield for the non-MS cultures was between 85 and $125 \%$ of the controls (Figure $5.4 \mathrm{~A}$ ).

It should be emphasized that the cell yields for MS samples at any single

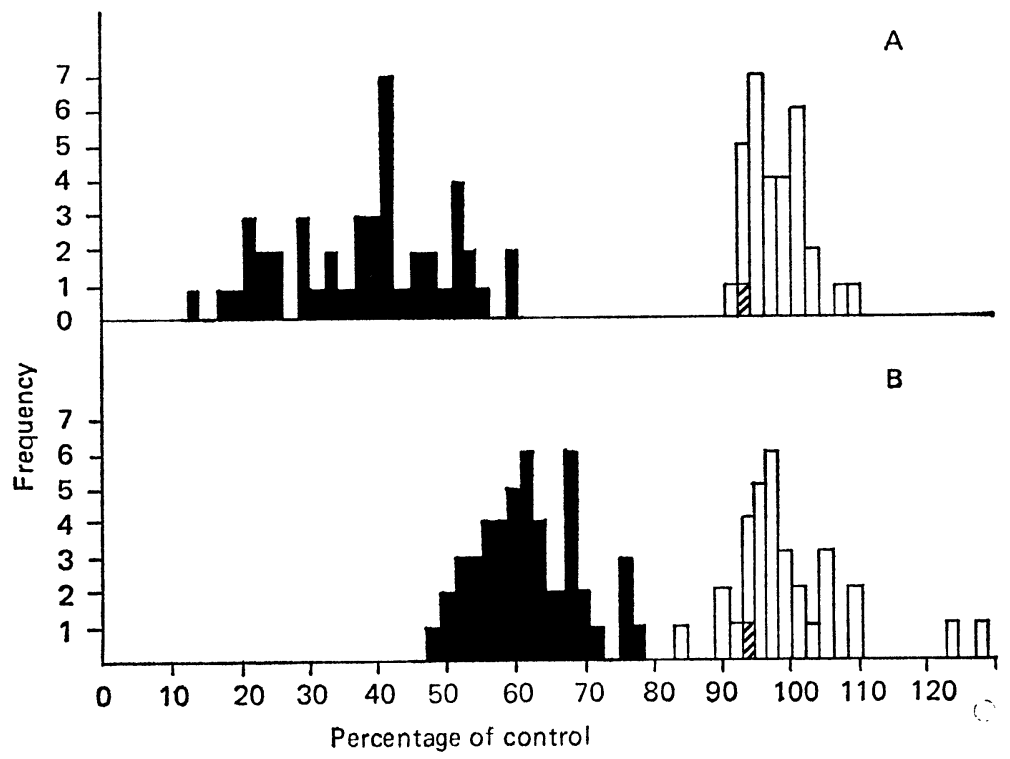

Figure 5.4 A: Frequency distribution of the average per cent cell yields from passage 3 to 5 , and Io to I6 or I7; per cent cell yields were averaged for each MS and each non-MS treated sample. Solid bars=MS samples; open bars=non-MS samples; cross-hatched bars $=$ MS sample in non-MS range.

B: Frequency distribution of the per cent cell yields at the 3 rd passage after treatment with cell-free lysates of passage I6 or I 7 of MS and non-MS treated cultures. Designation of bars is the same as in Figure 5.4A 
passage are occasionally greater than $80 \%$ of control. The key point is the average of the values obtained over a series of passages. For example, in the experiment noted above in which values for passage 3 were analysed, $20 \%$ of 7I samples had values higher than $80 \%$ of control. Virtually all of these 'negative' samples were found to be positive for the PAM cell effect when yields were averaged over an additional extended series of passages. Likewise, at any given passage a few non-MS samples have values less than $80 \%$ of control. However, over a series of passages the average yield values for all non-MS treated cultures were greater than $80 \%$ of control values.

Although the decreased PAM cell yields persisted at least through the I 7 th passage, there remained the question of whether the decreased yield was a consequence of the continuing presence of the agent or an initial alteration that persisted even after the causative agent had disappeared. To answer this question, 46 of the MS-treated PAM cultures at the final passage were frozen and thawed three times. These cell-free lysates were then used to infect fresh PAM cultures. The per cent yields at passage 3 have been arranged in a histogram (Figure 5.4B). All of the MS-treated cultures exhibited a decreased yield at the 3 rd passage except one, the same sample which had failed to cause a decrease from passage 3 to 17 , following the primary treatment. Combining the $46 \mathrm{MS}$ samples tested in this experiment with the five tested previously, the results show that 50 of $5 \mathrm{I}$ MS samples contained a small, self-replicating virus. By contrast, none of 36 non-MS samples appeared to contain a similar agent.

Filtration experiments established that for 43 of 45 samples (cell-free lysates from passage I6 or I7) tested, the size of the agent present in late passage MS-treated PAM cells is between 50 and $25 \mathrm{~nm}$. This is consistent with the size found for the agent in a pool of five MS brain homogenates. The establishment of the size of the agent in PAM cells, many passages after treatment, is significant for several reasons. PAM cells contain C-type particles ${ }^{10}$, and the MS-induced effect on cell yield might be mediated through an initially induced modification of the C-type particles, and their subsequent interaction with PAM cells. The replicating agent present in PAM cells I6 or I7 passages after treatment might then be this modified Ctype particle. This interpretation appears to be extremely unlikely, in that the size of the causative agent in late passage cell-free lysates is much less than the size of C-type particles. Finally, the size of this virus also differentiates it from the paramyxoviruses that have been isolated from MS material on rare occasions ${ }^{20,2 I}$.

Recently, Smith et al.22 showed that MS-treated PAM cells (and only PAM cells) produced an antigen which reacted in radioimmunoassay with approximately $30 \%$ of MS sera. Furthermore, they showed that some MS 
sera contained an agent which replicated in PAM cells and, in this manner, produced the antigen used in the radioimmunoassay test.

\section{ENHANCED HAEMAGgLUTINATION (HA) BY MS-TREATED PAM CELLS}

When mixed together, rhesus monkey RBCs and PAM cells undergo what macroscopically appears to be HA (microscopic examination suggests that mechanisms other than classic HA are operating) ${ }^{23}$. After 33 tests performed at different times under somewhat different conditions, we found the following:

(I) In any single test, MS PAM cell titres were invariably equal to, or higher than, those of control PAM cells exposed to non-MS tissues. The titre difference was as great as 32 -fold in some cases.

(2) In I I of the tests, the MS PAM cells had HA titres of I: 64 or higher, whereas in none of 33 tests did the normal controls exceed I: 32 .

(3) In $85 \%$ of the tests, HA titres of MS cultures were higher than control titres.

These results are important for three reasons: (a) it may prove to be an additional way to quantitate the MS-associated virus, $(b)$ it provides additional evidence that MS-treated PAM cells are different from non-MS treated cells; $(c)$ it gives a facile means to search for antibody, which might be directed against either the MS-associated virus or antigenic changes induced in cells treated with the virus.

\section{REDUCTION IN THE TOTAL CELL YIELD OF PAM CELLS INDUCED BY SCRAPIE MATERIAL}

Exposure of PAM cells to brain homogenates from mice infected with scrapie caused a decrease in total cell yield, which persisted from the 2nd or 3 rd passage to the I 8 th passage after treatment ${ }^{13}$. The effect was elicited by each of the eight independent scrapie isolates tested. Lysates prepared from cultures I6 passages after treatment with scrapie caused the decrease when applied to fresh PAM cultures. Mice inoculated with I4th and I8th passage lysates developed a reduced percentage of PMN by five weeks, and scrapie disease by six to nine months after inoculation. Based on the total dilution from treatment of the PAM cultures with scrapie material to the preparation of the lysates, we conclude that the agent(s) responsible for the reduced PAM cell yield, the decreased per cent PMN and the induction of scrapie disease had replicated in the PAM cells. By filtration, the diameter of the agent causing the reduction in cell yield was estimated to be between 25 and $50 \mathrm{~nm}$. 


\section{Discussion}

The idea that virus plays a significant role in the aetiology of MS was founded primarily on two early findings: (I) epidemiological studies that were consistent with viral aetiology ${ }^{24}$, and (2) immunological surveys showing that MS patients had higher measles antibody titres than matched controls ${ }^{25}$. From these studies plus others the search for an infectious agent in MS has taken the following routes:

(I) Animals: The search has been aimed at obtaining an animal model system in which an MS-like disease would occur.

(2) Tissue culture: Here, early unfruitful efforts at finding classical in vitro viral infections with attendant CPE etc. have given way to more sophisticated, indirect approaches such as co-cultivation and cell fusion with cells known to be susceptible to a presumed MS virus (primarily members of the paramyxovirus group) ${ }^{20,21}$.

(3) Electronmicroscopy: The examination of thin sections has also largely been geared toward a search for paramyxovirus particles and/or nucleocapsids ${ }^{26}$.

(4) Immunology: Here the approach has been to search for antibody against presumed MS virus in sera and CSF of MS patients. Again, the emphasis has been on the paramyxovirus group ${ }^{25}$.

Consideration of these approaches and their results so far provide us with the following current picture:

(I) Despite the success of passaging kuru and Jacob-Creutzfeldt into experimental animals and producing a similar disease ${ }^{27}$, efforts with MS have not yielded an animal model system.

(2) The techniques of co-cultivation and cell fusion led to the isolation of measles virus from a number of SSPE cases $^{28}$, and the initial successes with studies on MS in which a measles virus was isolated from one case and a parainfluenza virus from two cases $^{20,21}$. However, extensive studies since then, involving many MS samples, have failed to yield additional virus isolates $29 \cdot 30$.

(3) With electronmicroscopy, tubular structures were seen which were similar in size and appearance to paramyxovirus nucleocapsids ${ }^{26}$. However, extensive work in this area has shown that similar structures are seen in inflammatory conditions in which an infectious agent is not incriminated ${ }^{31}$. Furthermore, some researchers claim that the structures seen in MS differ in appearance from paramyxovirus nucleocapsids ${ }^{32}$. Attempts to label these tubules/nucleocapsids with measles and parainfluenza I virus antisera, using 
the immunoperoxidase method, have failed ${ }^{32}$. The only other report in the press is of coronavirus-like particles in MS brain ${ }^{33}$. However, the particles were seen in only one brain out of the $\mathrm{I} 2$ examined.

(4) In a number of immunological surveys, sera from affected persons have been tested for antibody against a wide range of known viruses in the hope of detecting increased antibody titres against a given virus. This has yielded the important finding that MS patients exhibit an increased antibody titre, both in serum and CSF, against a number of viruses, most strikingly measles 25,34 . The relationship of the elevated antibody titres to the aetiology of MS is questionable on several grounds: (a) the increase in antibody titre is not restricted to a single virus. This suggests that either there are multiple causes of MS, or the antibody increases are related to a more general change in immunological reactivity34; $(b)$ attempts to absorb the oligoclonal IgG bands found in MS CSF ${ }^{35}$ with measles virus failed ${ }^{36} ;(c)$ the increases in antibody titres against measles virus may not be correlated with MS disease per se, but rather with the HLA types which predominate in the MS population $^{37}$.

By contrast, our approach has involved a search for virus 'footprints', rather than disease or CPE. We did not expect to get disease in our test animals, but rather examined MS-infected mice for subclinical changes in physiological and biochemical parameters. Nor did we expect to find overt virus-induced changes, such as CPE, in our MS-treated tissue culture systems. Instead, we have looked for subtle changes in cell growth and surface characteristics. Using these approaches, we have accumulated some compelling evidence for MS-associated virus. This evidence includes the following key points:

(I) There is a small virus-like agent in MS tissues which causes a reduction in the percentage of circulating PMN4. This work has recently been confirmed and extended to include evidence of neutralizing antibodies ${ }^{14.15}$. Unfortunately, this system is unreliable, in view of difficulties we and others have had in obtaining suitably healthy and/or responsive mice.

(2) MS tissues harbour a small virus-like agent which causes a reduction in PAM cell yields, ${ }^{90}$. To date this virus has been found in 50 of $5 \mathrm{I}$ MS samples examined. The sample collection included serum, plasma and CSF, in addition to brain and other solid tissues. Recently, it has been shown that MS-treated PAM cells produced an antigen which reacted in a radioimmunoassay with approximately $30 \%$ of MS sera ${ }^{22}$.

(3) MS-treated PAM cells showed an increased ability to haemagglutinate rhesus red blood cells ${ }^{23}$.

It is interesting to compare the results that we have obtained for scrapie 
and for MS. Material from each disease causes a decrease in PMN in mice and a reduction in PAM cell yields4,5,9-13. The PMN agent from each disease replicates in mice and in treated PAM cells. The PAM cell agent from each disease replicates in PAM cells. The characteristics of the changes in mice and in PAM cells are quite similar. Thus, the time of appearance and the extent of the reduction in PMN percentages and of the reduction in PAM cell yields is quite similar following inoculation with material from the two diseases. The diameter of the PMN and PAM cell virus(es) in both diseases was $25-50 \mathrm{~nm}$ by millipore filtration analysis. The only difference in the responses induced by MS and scrapie material is that scrapie contains an infectious agent which causes disease in mice. The interrelationship of the viruses causing the various effects noted poses many interesting questions. Are the PMN and PAM cell effects in MS produced by the same virus or by two different viruses? The same question applies to the effects induced by scrapie tissue. In scrapie, the disease-producing agent is separable from the virus(es) causing PAM cell reduction and PMN percentage reduction. Is there a disease-producing agent in MS material which is separable from the PMN and PAM cell virus(es)? What is the relationship between the PMN and PAM cell virus(es) found in MS and those found in scrapie? Can the PMN and PAM cell virus(es) in MS interfere with the disease-producing agent of scrapie? The questions abound. Certainly, a key approach to a number of these questions is the study of the cross-reactivity of the MS PMN neutralizing antibody described by Henle et al.15.

One aspect of the PMN and PAM cell work should be stressed. This is a blood-borne virus. For the PMN virus, Henle et al.15 have demonstrated virus activity in the serum. In our original work, PMN virus was found in two of two MS sera examined 4 and in subsequent unpublished data we have found PMN activity in approximately $70 \%$ of 28 sera. In our PAM cell work, all $30 \mathrm{MS}$ sera and plasma samples tested were shown to contain virus, and Smith et al. ${ }^{22}$ have reported an agent in MS serum that replicated in PAM cells.

The presence of the PMN and PAM virus(es) in serum and plasma from MS patients has a number of important implications. First, presence in the blood means the virus(es) should be found in most organs, and in fact, our results show that, in addition to brain, the agent(s) is found in spleen, kidney and lymph gland. Second, the fact that the agents are blood-borne suggests the possibility of circulating antigen (agent)-antibody complexes. In the case of the PMN agent, there is such evidence ${ }^{15}$. Third, the fact that the virus(es) is present in easily obtained body fluids increases the possibility that a test for its presence could be used as a diagnostic aid. Should the MS-associated virus(es) prove to be the cause of MS, then its presence in blood has some 
additional important consequences. The possibility that MS could be transmitted by transfusion should be considered, and a retrospective study of this has been initiated ${ }^{38}$. In this study, an attempt will be made to determine the MS status of individuals who received transfusions with blood supplied by MS patients in either the clinical or preclinical phase of disease. The presence of causative agent in serum would also permit vectors to play a role in transmission. Could the geographical incidence of MS disease be related to specific vectors? Is the high incidence of antibodies to the $\mathrm{PMN}$ agent in the general population in Africa ${ }^{15}$ related to extensive spread of the virus in the young by the high population density of various insect vectors or of a specific vector?

Changes in the proportion of various leukocyte types are usually related to responses to new antigenic stimuli. An alternative possibility is that a virus could act directly and specifically upon one or more of the leukocyte subtypes or precursor cells, thereby affecting the proportion and/or the responsiveness of the various cell types. In mice it would appear that the MSassociated virus acts directly upon mature leukocytes or their precursors, since the reduction in PMN percentage occurs very rapidly. In humans with MS, PMN levels remain normal, but there is evidence of a change in the proportion of $\mathrm{T}$ and $\mathrm{B}$ cells. ${ }^{39} \mathrm{It}$ is possible that the change seen in the proportion of leukocyte types in MS is the result of the direct action of the MSassociated virus, and that this in turn leads to the altered immune potential described for MS patients $25,34,40-42$. In this manner, it is possible that the modulation of the disease process which is characteristic of MS is related to perturbations in the interaction between MS-associated virus and leukocytes. Certainly, if the PMN and PAM cell effects are induced by the causative agent of MS, then the fact that it is present in blood and may act upon leukocyte cell types will add entire new dimensions to the studies of diagnosis, pathogenesis and transmission of this disease.

To conclude, our findings represent the strongest evidence thus far for an MS-associated virus. This discovery raises the hope that this virus is the causative agent of MS disease. Along with this hope, however, comes the frustrating problem of establishing such a causal relationship. The resolution of the question of causality requires progress in several areas. We must improve the means of quantitating the virus so that we can continue its muchneeded purification and characterization. We must develop immunological probes which would furnish the means to investigate the distribution of the virus at the population, individual and cellular levels. We must determine the biochemical and morphological characteristics of the virus, so that it can be related to known virus groups. With these capabilities, we should then be able to establish firmly the role of this virus in MS. 


\section{Acknowledgements}

The authors wish to thank Drs Helen Warner and Richard Kascsak for their helpful criticism of the manuscript.

\section{References}

I. Palsson, P. A., Pattison, I. H. and Field, E. J. (1965). Transmission experiments with multiple scletosis. In: NINDB Monograph No. 2, Slow, latent and temperate virus infections. Eds. D. C. Gajdusek, C. J. Gibbs and M. Alpers. Pp. 49-54

2. Field, E. J. (1966). Transmission experiments with multiple sclerosis: an interim report. Br. Med. J., 2, 564

3. Chandler, R. L. (1963). Experimental scrapie in the mouse. Res. Vet. Sci., 4, 276

4. Carp, R. I., Licursi, P. C., Merz, P. A. and Merz, G. S. (1972). Decreased percentage of polymorphonuclear neutrophils in mouse peripheral blood after inoculation of material from multiple sclerosis patients. J. Exp. Med., 136, 6I8

5. Licursi, P. C., Merz, P. A., Merz, G. S. and Carp, R. I. (1972). Scrapie-induced changes in the percentages of polymorphonuclear neutrophils in mouse peripheral blood. Infect. Immun., 6, 370

6. Hunter, G. D. (1972). Scrapie, a prototype slow infection. J. Infect. Dis., I25, 427

7. Outram, G. W. (1972). Changes in drinking and feeding habits of mice with experimental scrapie. J. Conp. Pathol., 82, 4I5

8. Merz, P. A., Merz, G. S. and Carp, R. I. (1973). Higher frequency of a protein band in the cerebrospinal fluid from scrapie mice. Res. Vet. Sci., 14, 392

9. Carp, R. I., Merz, G. S. and Licursi, P. C. (1974). Reduced cell yields of mouse cell line cultures after exposure to homogenates of multiple sclerosis tissues. Infect. Immun., 9, I0I I

Io. Carp, R. I., Licursi, P. C. and Merz, G. S. (1975). Multiple sclerosis induced reduction in the yield of a mouse cell-line. Infect. Immun., II, 737

II. Carp, R. I., Merz, G. S. and Licursi, P. C. (1975). A non-cytopathic infectious agent associated with MS material. Neurology, 25, 492

I2. Carp, R. I., Merz, G. S. and Licursi, P. C. (1976). A small virus-like agent found in association with multiple sclerosis material. Neurology, 26, 6 (2), 70

I3. Carp, R. I., Merz, G. S. and Licursi, P. C. (1976). Scrapie in vitro: Agent replication and reduced cell yield. Infect. Immun., I4, I63

I4. Koldovsky, U., Koldovsky, P., Henle, G., Henle, W., Ackermann, R. and Haase, G. (1975). Multiple sclerosis-associated agent: Transmission to animals and some properties of the agent. Infect. Immun., I2, I355

I5. Henle, G., Koldovsky, U., Koldovsky, P., Henle, W., Ackermann, R. and Haase, G. (1975). Multiple sclerosis-associated agent: Neutralization of the agent by human sera. Infect. Immun., I2, I367 
I6. Brown, P. and Gadjusek, D. C. (1974). No mouse PMN leukocyte depression after inoculation with brain tissue from multiple sclerosis or spongiform encephalopathies. Nature (London), 247, 217

17. McNeill, T. A., Killen, M. and Trudgett, A. (1974). Mouse granulocyte precursors and multiple sclerosis. Nature (London), 249, 778

I8. Carp, R. I., Merz, P. A., Licursi, P. C. and Merz, G. S. (1973). Replication of the factor in scrapie material that causes a decrease in polymorphonuclear neutrophils J. Infect. Dis., 128, 256

19. Dickinson, A. G., Taylor, D. M. and Fraser, H. (1974). Depression of polymorph counts by various scrapie agents. Nature (London), 248, 5 IO

20. ter Meulen, V., Koprowski, H., Iwasaki, Y., Kackell, Y. M. and Muller, D. (1972). Fusion of cultured multiple sclerosis brain cells with indicator cells: Presence of nucleocapsids and virions and isolation of parainfluenza-type virus. Lancet, ii, I

21. Field, E. J., Cowshall, S., Narang, H. K. and Bell, T. M. (1972). Viruses in multiple sclerosis? Lancet, ii, 280

22. Smith, K. O., Gehle, W. D., Madden, D. L. and Fucillo, D. A. (I976). Viral and cellular antibodies in multiple sclerosis (MS) and normal subjects' sera. Ann. Meet. Am. Soc. Microbiol. Abstr., p. 254

23. Warner, H. B., Carp, R. I. and Narducci, R. (1976). Haemagglutination-like responses in multiple sclerosis-treated cells. Lancet, $\mathbf{i}, 688$

24. Leibowitz, U. (I97I). Multiple sclerosis: Progress in epidemiologic and experimental research: A review. J. Neurol. Sci., 12, 307

25. Adams, J. M. and Imagawa, D. T. (I962). Measles antibodies in multiple sclerosis. Proc. Soc. Exp. Biol. Med., III, 562

26. Prineas, J. (I972). Paramyxovirus-like particles associated with acute demyelination in chronic relapsing multiple sclerosis. Science, $\mathbf{1 7 8}, 760$

27. Gibbs, Jr., C. J. and Gajudsek, D. C. (1973). Experimental subacute spongiform virus encephalopathies in primates and other laboratory animals. Science, 182, 67

28. Horta-Barbosa, L., Fuccillo, D. A., Sever, J. L. and Zeman, W. (I969). Subacute sclerosing panencephalitis: Isolation of measles virus from a brain biopsy. Nature (London), 22r, 974

29. Barbosa, L. H. and Hamilton, R. (I973). Virological studies with multiple sclerosis brain tissues. Lancet, i, I4IS

30. Ammitzboll, T., Offner, H., Clausen, J., Kobayasi, T., Asboe-Hansen, G., Hyllested, K. and Fog, T. (1976). Lysolecithin fusion of cells from multiple sclerosis patients with vero cells. Acta Neurol. Scand., 53, I37

3I. Lampert, F. and Lampert, P. (1975). Multiple sclerosis. Morphologic evidence of intranuclear paramyoxvirus or altered chromatin fibers? Arch. Neurol., 32, 425

32. Dubois-Dalcq, M., Schumacher, G. and Sever, J. L.(I973). Acute multiple sclerosis: Electronmicroscopic evidence for and against a viral agent in the plaques. Lancet, ii, $\mathrm{I} 408$

33. Tanaka, R., Iwasaki, Y. and Koprowski, H. (1976). Intracisternal virus-like particles in brain of a multiple sclerosis patient. J. Neurol. Sci., 28, I2 I

34. Norrby, E., Link, H., Olsson, J., Panelius, M., Salmi, A. and Vandvik, B. (1974). 
Comparison of antibodies against different viruses in cerebrospinal fluid and serum samples from patients with multiple sclerosis. Infect. Immun., Io, 688

35. Link, H. (1972). Oligoclonal immunoglobulin G in multiple sclerosis brains. J. Neurol. Sci., 16, I03

36. Norrby, E. and Vandvik, B. (1974). The relationship between measles virusspecific antibodies and oligoclonal IgG in the cerebrospinal fluid (CSF) in patients with subacute sclerosing panencephalitis (SSPE) and multiple sclerosis (MS). Med. Microbiol. Imniunol., 160, 233

37. Paty, D. W., Furesz, J., Boucher, D. W., Rand, C. G. and Stiller, C. R. (1976). Measles antibodies as related to HLA types in multiple sclerosis. Neurology, 26, 65I

38. Zander, H. (1975). Transmission of multiple sclerosis by blood transfusion? J. Neurol. Sci., 24, 505

39. Oger, J. F., Arnason, B. G. W., Wray, S. H. and Kistler, J. P. (1975). A study of $\mathrm{B}$ and $\mathrm{T}$ cells in multiple sclerosis. Neurology, 25, 444

40. Utermohlen, V. and Zabriskie, J. B. (I973). A suppression of cellular immunity in patients with multiple sclerosis. J. Exp. Med., 138, I59I

4I. Lamoureux, G., Giard, N., Jolicœur, R., Toughlian, V. and Desrosiers, M. (1976). Immunological features in multiple sclerosis. Br. Med. J., I, I83

42. Levy, N. L., Auerbach, P. S. and Hayes, E. C. (1976). A blood test for multiple sclerosis based on the adherence of lymphocytes to measles-infected cells. N. Engl. J. Med., 294, 1423 